\title{
Further Convergence Management to Build a More Resilient Education System for International Students at Tsinghua University in COVID-19 Pandemic Period
}

\section{以趋同管理促进构建更有韧性的人才培养体系： 新冠疫情中清华大学国际教育实践}

\author{
Qingling Liu (刘清伶) \\ Nan Zou (邹楠) \\ Tsinghua University, China \\ 清华大学, 中国
}

\begin{abstract}
(摘要)
COVID-19 disrupts regular educational order and poses significant challenges to international education. In the face of the uncertain development of the pandemic, Tsinghua University has been actively exploring to build a more resilient education system by further promoting convergence management of the local and international students. Based on the organization system theory, we explain the necessity of convergence management, review Tsinghua's responses to the COVID-19 crisis, and introduce the practices in building a more resilient education system, and discuss the future for promoting system resilience.

新冠肺炎疫情打乱了正常的教育秩序，对国际学生培养带来巨大挑战。面 对疫情发展的不确定性, 清华大学深入推进趋同管理, 积极探索构建更有 韧性的人才培养体系。本文以组织系统理论为指导, 说明中外学生趋同管 理的必要性, 回顾清华应对疫情危机的系统建设历程, 介绍构建更有韧性 国际教育体系的实践，进而讨论提升系统韧性的未来展望。
\end{abstract}


Keywords (关键词) : convergence management, resilience, international student, education system, COVID-19 (趋同管理, 㓞性, 国际学生, 培养体系, 新冠疫情)

\section{前言}

新冠肺炎疫情在所有区域都严重阻碍且逆转了《2030 年可持续发展议程》 的执行进展 (Economic and Social Council, 2021)。截至 2020 年 4 月 5 日，近 16 亿学生无法上学 (赵章靖, 2020)。疫情打乱了人们生活的各个方面, 对 青年 (18-29 岁) 造成系统而深远的巨大影响：学校与培训中心关闭影响到 $73 \%$ 以上的受教育青年并会影响到就业，还造成心理、权益、社会行为等 方面的不利影响 (International Labour Organization, 2020)。

“因为疫情， 2020 年将成为人类历史上的分水岭。”(邱勇, 2020) 疫 情危机还在继续并持续影响着清华大学的国际学生培养。疫情爆发时正值 寒假, 当时大批国际学生离开了中国, 绝大部分学生未能如期返回。438 所高校在籍的 16 万多国际学生中, 在中国境内的只有不到 4.6 万人 (李梅 花等, 2020)。截至 2020 年底, 清华 3300 多名国际学生中, 仅有不到 1100 人在中国境内。客观形势要求采取积极应对策略, 化解疫情对国际学生培 养带来的不利影响。

大学是系统, 通过高效的组织, 可以将系统资源和要素统筹协调起来, 为人才培养服务。在疫情情境下, 人才培养工作面临着巨大挑战, 如何在 防控好疫情的基础上开展国际学生培养, 是清华需要迅速解决的重要课题。

\section{构建中外趋同的人才培养体系}

系统是由相互关联、相互作用、相互制约的组成部分所构成的具有某种功 能的整体, 由子系统和要素构成, 开放系统是指与系统的外部环境有交流 的系统 (钱学森, 2001)。由关联的部分联结或结合在一起是所有系统的共同 特点，这些联结使得系统组成部分之间相互依赖。但这种依赖或联结的程 度并不完全相同，故组织也有自我调节系统的组织与松散偶联系统的组织 (理查德·斯科特, 杰拉尔德·戴维斯, 2011)。

大学是由师生员工等要素为人才培养目的而组织起来的系统, 具有很 强的自我调节能力。新冠肺炎的全球传播和病毒对全体人类的攻击客观上 要求大学做出系统性的应急反应和部署, 并随形势变化调整措施, 以更好 地应对疫情, 开展人才培养工作, 并促进自身持续发展。新冠病毒对所有 师生员工的危害和疫情防控相关法律政策客观上也要求学校开展系统防控 和统一行动, 这也为加强中外学生趋同管理提供了客观依据。

趋同管理要求对国际学生的管理方式与国内学生大体相同 (徐艳春, 李 文武 \& 鲁玲, 2016)。趋同管理当然并非因疫情而起, 其根本原因在于中国 教育的内在发展。一是中国从教育大国向教育强国转变, 中国教育能够培 养出大师。二是中国教育国际化的需要。中国已成为世界第三留学目的地 
国, 以往特殊化的国际学生管理模式难以适应教育发展形势, 越来越需要 中外趋同。三是对人才培养认识的深化。构建人类命运共同体成为指导人 才培养的重要思想，价值塑造、能力培养、知识传授 “三位一体” 成为基 本教育理念，全员全程全方位育人 “三全育人”成为基本要求，德智体美 劳全面发展的全球胜任力人才成为重要培养目标。“促进中外青年共同成 长，为实现中华民族伟大复兴和构建人类命运共同体提供人才支撑，是来 华留学事业新的时代使命。” (丽金梁, 2021)

为适应新形势，人才培养上必须深入变革，加强中外趋同。清华近年 来一直在推进中外趋同，努力 “实现中外学生的培养趋同和管理趋同、交 流融合与文化认同，建设国际化校园，全面提升面向国际学生的教育、管 理与服务工作质量” (清华大学, 2018), 已初步形成国际化、趋同化、专 业化、协同化的国际学生培养体系 (刘清伶 \& 邹楠, 2021)。

这一体系是学校人才培养体系的组成部分，同时其子系统也落实趋同 要求。国际学生招生管理归口至招办, 教学与学位归口至教务处、研究生 院, 在学校相关委员会领导和院系工作队伍的协作下构成招生教学系统。 学生工作由学生处、研工部牵头, 在学校学生工作指导委员会领导下, 与 院系学生工作系统联合构成学生工作体系。住宿、餐饮、安全、医疗、保 险等方面校内外各方协作, 构成服务保障体系。国际学生学者中心作为国 际学生归口部门在国际学生入学教育、外事管理、中外融合等发面发挥主 导作用, 与其他相关子系统及要素共同构成国际学生培养体系。清华在多 层面上推进中外学生趋同管理, 创造了有利于国际学生学习与发展的良好 环境, 提升了培养效果 (邹楠, 刘清伶 \& 杨静, 2020)。

构建更有韧性的人才培养体系, 消减疫情为国际学生培养带来的破坏 性影响, 是清华面临的重要课题。清华充分发挥趋同管理优势, 进行了积 极探索。

\section{危机情境下的人才培养体系建设}

危机情境下中外趋同的人才培养体系建设是否有效？这可以用危机管理 4R 模式进行分析。所谓 4R 是指缩减 (Reduction), 预备 (Readiness), 反应 (Response), 恢复 (Recovery) 四步管理法, 即减少危机情境、做好应对准备、 尽力应对危机、从危机中恢复，危机管理的结果应是组织㓞性 (Resilience) 即有效生存与反应能力的提升 (罗伯特·希斯, 2001)。

中国 “用 1 个多月的时间初步遏制疫情蔓延势头，用 2 个月左右的时 间将本土每日新增病例控制在个位数以内，用 3 个月左右的时间取得武汉 保卫战、湖北保卫战的决定性成果，进而又接连打了几场局部地区聚集性 疫情歼灭战，夺取了全国抗疫斗争重大战略成果。”(习近平, 2020) 国家 成功抗疫为清华应对疫情并做好人才培养工作提供了支持。 


\section{缩减阶段形成危机预防体系}

国家的危机管理体系为清华的危机管理提供了指南。《中华人民共和 国突发事件应对法》明确要求建立健全突发事件应急预案体系，《国家突 发公共事件总体应急预案》提供了系统的危机应对指南, 《国家突发公共 卫生事件应急预案》为防控疫情及其危害提供了参考, 《突发事件应急预 案管理办法》对预案编制和管理提出明确要求。清华制定了总体预案和各 类突发事件应急预案, 形成了应急预案体系。其中校园大规模传染病流行 事件应急预案详细规定了各方面安排, 为疫情防控提供了重要指南。此外, 2003 年学校在防控非典型性肺炎中形成的有效经验和防控体系为新冠肺炎 疫情防控提供了参考, 而且清华也一如既往坚决防控新冠肺炎疫情。这些 都对减少和应对学校的疫情危机情境有积极作用。

\section{预备阶段构建疫情防控体系}

清华 “把全校师生员工的生命健康摆在首要位置，把疫情防控作为当 前最重要的工作”（清华大学，2020），迅速构建起疫情防控体系。明确 了防控原则。2020 年 1 月下旬迅速启动防控准备, 确立了 “高度重视、严 格迅速、积极主动、科学有效、早做准备” 的原则 (吴䈗君, 2020)。建立 起组织架构。2020 年 1 月 23 日成立由校党委书记和校长任双组长的新冠 肺炎疫情防控领导小组, 并陆续成立医疗保障等 15 个专项工作组, 其中 包括防控疫情学生工作组。及时沟通信息。通过信息门户网站等提醒师生 做好防护, 通知取消聚集类活动、暂停校园参观和场馆开放, 要求全体学 生不提前返校，并开通 24 小时热线。保障正常工作。当时虽正值春节期 间, 存在人员紧缺困难, 学校依然加强了值班值守安排, 保持校医院发 热门诊正常接诊, 并积极部署排查工作, 对各二级单位提出明确防控要求。 明确教学计划。为稳定教学秩序, 促进疫情防控, 决定 “延期开学、如期 开课”, 利用寒假组织在线教学培训, 准备线上教学。

\section{反应阶段建立工作落实体系}

2020 年 2 月至 6 月是疫情防控关键反应阶段, 清华采取有效措施, 各 部门和全校师生员工共同参与、分工协作, 形成系统的工作落实体系, 疫 情防控与人才培养齐抓共进。加强校园管控。学生相关部门与院系严格出 入校审批, 各单位加强场所管控、校园活动管控, 饮食中心强化用餐管理 等, 降低传染风险。加强信息化工作。2 月起信息办、信息化技术中心与 学生相关部门写作，陆续开发上线了学生健康和出行情况报告系统、涉疫 风险情况报告系统、学生进出校审批系统等, 国际学生学者中心协调上线 了相关双语系统。保障教学科研。在教学专项工作组下成立三个在线教学 专家组和一个学生学习保障工作组, 指导与保障在线教学。2 月 3 日全校 师生线上同上一堂课，拉开在线教学的序幕。加大发展支持力度。向受疫 情影响产生经济困难的学生包括国际学生提供特殊困难补助, 加强信息服 
务和线上学习、心理、职业发展等方面的指导, 在保证质量的前提下支持 学生按时毕业。2020 年春季学期全校共开设在线教学课程 4471 门次(邱勇, 2020), 能开尽开, 科研上在新冠病毒机理研究、疾病诊断等方面产生了一 系列科研成果, 全年国际学生毕业人数超过往年。

\section{恢复阶段推进工作融合体系}

根据教育部和北京市部署, 学校 6 月初启动学生返校并准备新生入学 工作，构建了兼顾境内境外、线上线下、自愿与要求相融合的有序工作体 系。为来校师生上线了双语化的 “清华紫荆” 小程序，制定实施分批返校 方案和安全预案, 开展恢复工作。2020 年 6 月 6 日起首先安排毕业年级学 生分批次自愿返校。虽然由于 6 月 11 日以来北京疫情突转严峻, 这次返校 工作被迫中止，在校毕业学生也推迟离校，但是 6 月 22 日、23日的研究生 毕业典礼和本科生毕业典礼还是采用线上线下相结合的形式如期举行, 全 球双语直播, 最大限度满足境内外毕业生需求。随着疫情再次得到控制, 学校从 2020 年 8 月 15 日起组织学生有序返校和新生报到。8 月中下旬开始 韩国留学生也可办理来华学习签证入境中国, 学校积极提供入境帮助与校 内生活服务, 数百名国际学生从境内外陆续来校学习。2020 年秋季学期在 校学生落实常态防控要求, 开展线下教学, 不能到校的学生坚持线上教学。 以线上线下融合的方式持续开展各项工作，适应了疫情情况下国际学生培 养需要。

\section{危机管理中增强人才培养体系的韧性}

如前所述, 组织韧性 (Resilience) 是指有效生存与反应能力, 也是危害中的 系统通过保护和恢复基本结构和功能等方法，及时有效抵御、吸收、适应 灾害影响和灾后恢复的能力 (范维澄, 2015)。清华以趋同管理方式建设起国 际学生培养体系, 又在疫情危机应对中对体系加以完善。危机管理的各项 努力有效维护了学校人才培养的核心功能, 提升了人才培养体系的韧性。 2021 年清华的国际学位生新生报到率和报到人数与 2020 年相差不到 1 个百 分点, 比 2019 年下降 6 个多百分点, 三年的报到率均在 $72 \%$ 以上, 总体稳 定。学校坚持对滞留境外的 2000 多名国际学生开展教学、指导等培养工作, 趋同管理下国际学生培养体系的韧性得以彰显。

清华大学的趋同管理实践对建设更有韧性的国际学生培养体系有何启 示? 这可以从组织结构、系统功能和工作效果等方面考察。

\section{完善结构, 共担责任, 统一要求}

新冠肺炎疫情给大学带来新的工作内容, 即疫情防控, 这要首先从完 善基本系统结构入手。为做好学生疫情防控工作, 清华大学建立防控疫情 学生工作组, 由学校分管学生工作的副书记领导, 学生部、研工部、国际 学生学者中心以及相关部门共同参与, 将包括国际学生在内的全体学生纳 入工作对象。工作组统筹安排学生疫情防控工作, 在信息采集、防控措施、 
教学保障等方面统一要求, 全体学生一视同仁, 消除了中外学生区别对待 的问题。如学校对保留宿舍但不能返校的国际学生与中国学生一样免收宿 舍费, 受到普遍认可。工作组统筹学生工作部门、安全保卫部门、医疗保 健部门和院系等共同开展国际学生管理服务, 协同承担危机应对、管理服 务、发展支持等方面的责任。如向在校国际学生同样提供免费新冠肺炎疫 苗接种。通过完善结构, 最大化降低了风险, 提升了系统能力和可持续性, 为更好地开展人才培养工作提供了有力支持。

\section{融合力量, 保持功能, 提高水平}

教学秩序是清华的基本秩序, 保障教学秩序是人才培养最核心的工作, 涉及包括 3000 多名国际学生学者在内的数万名师生员工, 需要集全校之 力尽力保障。学校 2020 年 2 月初就组织全校师生同上一堂课, 强化共同 体理念, 号召共同行动。在学校建设在线教学体系的同时, 国际学生学者 也主动参与到在线教学培训体系建设和教学技术指南编写等工作中, 积极 发挥主人翁精神。清华还统筹安排联系到包括国际学生学者在内的每一位 师生, “一人一策” 解决个性化问题, 兼顾各地区、各专业、各种情景下 不同教学需求, 努力保障一个都不落下。国际学生学者切实感受到了清华 共同体的力量, 积极参与到相关工作中。针对绝大部分国际新生不能入境 的情况, 国际学生入学教育也全部转为线上, 如期开展, 并开展多种形式 的线上线下融合式活动。这些举措切实保障了教学秩序和学校核心功能, 也促进了工作水平的提高。

\section{拓展路径, 完善系统, 优化效果}

人才培养工作因时因势而变, 国际学生培养尤其要顺应时势, 要以灵 活安排促进育人。北京时间 2020 年 3 月 9 日上午，疫情防控期间清华首场 硕士学位论文在线答辩会顺利举行, 参加答辩的是位国际学生。学校毕业 安排更加灵活, 增加学位审批次数, 加强科研和论文指导, 为学生按时毕 业创造积极条件。以发展支持促进育人。2020 年初向因疫情影响造成困难 的学生提供困难补助或技术支持, 2021 年秋季学期设立蒲公英计划, 共已 向 200 多名国际学生提供了资助, 促进其更好地投入学习。以示范力量促 进育人。清华积极承担社会责任, 2020 年春季学期把 2200 多门慕课和学 校的智慧教学工具免费向社会开放, 还与联合国教科文组织联合发起全球 大学特别对话，与武汉等地区的大学合作促进共同发展。学校 “自强不息、 厚德载物” 的行动是鲜活的教材, 国际学生深受鼓舞。2020 届波黑籍硕士 毕业生伊瓦娜在毕业典礼上表示清华给了她远见卓识, 并特别倡议毕业生 们团结起来为人类社会和美好未来而努力 (伊瓦娜, 2020)。

\section{结语及展望}

趋同管理是促进学校人才培养的正确选择。清华持续推进趋同管理, 在应 对新冠肺炎疫情中构建更有韧性的人才培养体系, 保障了教育教学不间断, 
促进了学校可持续发展, 也带动其他高校提升应对危机的能力。面向未来, 清华提出建设更开放、更融合、更具韧性的大学，这一理念也以 2021 大学 校长全球论坛《清华共识》的形式，为世界上 100 多所高校所认同。

可以预见，未来清华将会继续推进中外学生趋同管理，国际学生培养 体系将会继续完善, 这一体系以及清华人才培养体系的韧性将会继续增强, 人才培养能力也会持续提高。由于新冠肺炎疫情在短期内还会继续影响国 际学生培养, 危机应对体系将继续发挥作用。同时, 作为开放系统, 大学 未来也会遇到各种挑战, 需要提升人才培养体系韧性、进一步促进国际学 生培养。

鉴于目前大部分国际学生还无法正常来校学习生活, 学习、心理、经 济、社会、就业等多方面的压力还将持续, 面向未来, 大学需要提前部署, 在推进在线教育和保障教育质量的同时, 要系统考虑如何更好地为国际学 生提供发展支持, 让大学及其人才培养体系的韧性化为其所培养人才的韧 性，进而促进大学共同体乃至人类命运共同体的韧性。

\section{参考文献}

Economic and Social Council. (2021). Regional Cooperation in the Economic, Social and Related Fields: Report of the Secretary-General. https://www.un.org/ga/search/view_doc.asp?symbol=E/2021/15.

International Labour Organization. (2020). Youth \& COVID-19: Impacts on Jobs, Education, Rights and Mental Well-being. https:/www.ilo.org/wcmsp5/groups/public/ed_emp/documents/publication/ wcms 753026.pdf.

Scott, W. R., \& Davis, G.. (2000). Organizations and Organizing: Rational, Natural and Open Systems Perspectives. Routledge. https://doi.org/10.4324/9781315663371

范维澄. (2015). 构建智慧韧性城市的思考与建议. 中国建设信息化, (21), 2021. doi:CNKI:SUN:ZGJS.0.2015-21-012 李梅花, 隋祎宁, 孟翔冲等. (2020). 新冠肺炎疫情对来华留学生工作的影响 及对策调研报告. 来华留学年度报告.

郘金梁。(2021)。构建新时代国际学生教育管理体系。中国教育报。 https://baijiahao.baidu.com/s?id=1689818088987791155\&wfr=spider\&for= pc.

刘清伶, \& 邹楠. (2021). 以更高水平人才培养体系促国际学生成长. 神州学

人, 44-47. doi:CNKI:SUN:SZXR.0.2021-04-013

罗伯特·希斯. (2001). 危机管理. 中信出版社.

钱学森. (2001). 创建系统学. 山西科学技术出版社.

清华大学. (2018). 关于完善国际学生工作体系的若干意见.

清华大学. (2020). 同舟共济度时艰 众志成城战疫情 清华大学致广大师生员

工 的 一 封 信

https://weibo.com/ttarticle/p/show?id=2309404466167396827503. 
邱勇. (2020). 建设更开放、更融合、更有㓞性的大学 实现更加普惠的高质 量教育. https://www.tsinghua.edu.cn/info/1688/79321.htm.

吴篵君. (2020). 严密防范 周密部署 清华大学扎实开展新型冠状病毒感染的 肺炎疫情防控工作. https://www.tsinghua.edu.cn/info/1685/69269.htm.

习近平. (2020). 在全国抗击新冠肺炎疫情表彰大会上的讲话.

http://www.xinhuanet.com/politics/2020-10/15/c_1126614978.htm.

徐艳春, 李文武, \& 鲁玲. (2016). 高校来华留学生趋同化管理的研究. 教育教 学论坛, 11-12.

https://kns.cnki.net/kcms/detail/13.1399.G4.20161108.1430.012.html

伊瓦娜。(2020). 自强不息厚德载物在挑战中寻求成功方案. https://www.tsinghua.edu.cn/info/1681/79531.htm.

赵章靖. (2020). 新冠肺炎疫情冲击下全球教育的变化特征和趋势. 国家教育 行政学院学报, 59-69. doi:CNKI:SUN:GJXZ.0.2020-09-009.

邹楠, 刘清伶, \& 杨静. (2020). 清华大学中外学生趋同管理的实践与挑战. 国 际学生教育管理研究, 100-108. doi:CNKI:SUN:GJJG.0.2020-01-012.

QINGLING LIU (corresponding author) is Deputy Director of Tsinghua University International Students and Scholars Center. His research interests include international student education.Email: qliu@tsinghua.edu.cn

刘清伶 (通讯作者), 清华大学国际学生学者中心副主任。研究兴趣包括国 际学生培养。邮箱: qliu@tsinghua.edu.cn

NAN ZOU is Senior Manager of Tsinghua University International Students and Scholars Center. His research interests include international student management and service. Email: zounan@tsinghua.edu.cn

邹楠, 清华大学国际学生学者中心高级主管。研究兴趣包括国际学生管理 和服务。邮箱: zounan@tsinghua.edu.cn 